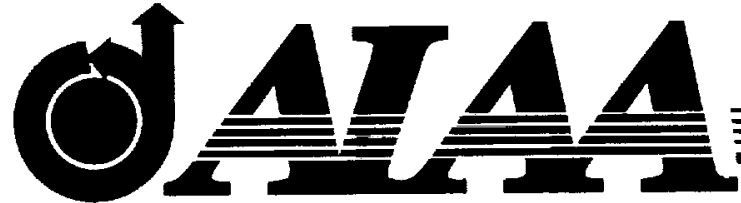 \\ AIAA 2002-0839 \\ Assessment of the Unstructured Grid Software TetrUSS for Drag Prediction of the DLR-F4 Configuration
}

Shahyar Z. Pirzadeh and Neal T. Frink NASA Langley Research Center, Hampton, VA

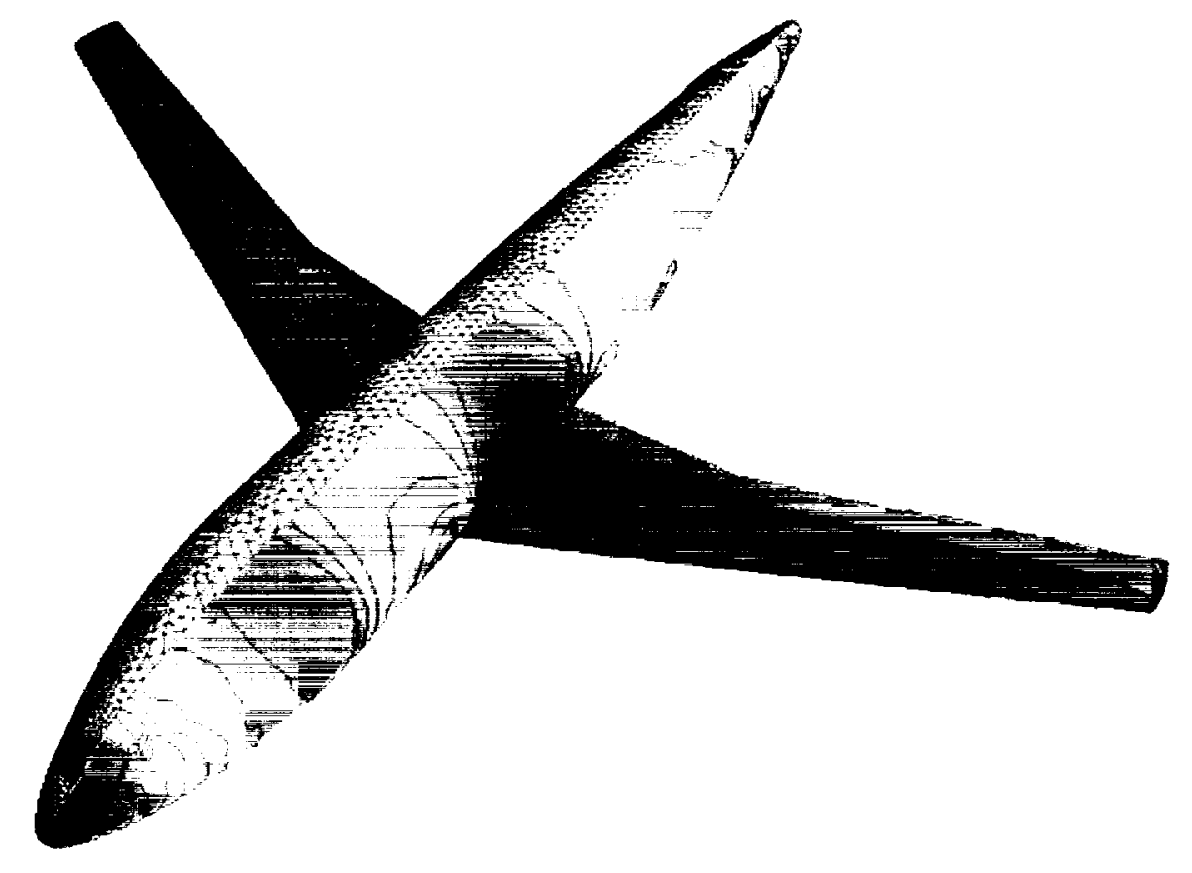

\section{0th AIAA Aerospace Sciences Meeting \& Exhibit January 14-17, 2002 / Reno, NV}



AIAA-2002-0839

\title{
Assessment of the Unstructured Grid Software TetrUSS for Drag Prediction of the DLR-F4 Configuration
}

\author{
Shahyar Z. Pirzadeh" and Neal T. Frink ${ }^{\dagger}$ \\ Acrodynamics, Aerothermodynamics, and Acoustics Competency \\ NASA Langley Research Center \\ Hampton, VA 23681-2199
}

\begin{abstract}
An application of the NASA unstructured grid software system TetrUSS is presented for the prediction of aerodynamic drag on a transport configuration. The paper briefly describes the underlying methodology and summarizes the results obtained on the DLR-F4 transport configuration recently presented in the first AIAA CFD Drag Prediction Workshop. TetrUSS is a suite of loosely coupled unstructured grid CFD codes developed at the NASA Langley Research Center. The meshing approach is based on the advancing-front and the advancing-layers procedures. The flow solver employs a cell-centered, finite volume scheme for solving the Reynolds Averaged NavierStokes equations on tetrahedral grids. For the present computations, flow in the viscous sublayer has been modeled with an analytical wall function. The emphasis of the paper is placed on the practicality of the methodology for accurately predicting aerodynamic drag data.
\end{abstract}

\section{INTRODUCTION}

Computational Fluid Dynamics (CFD) has matured to the point where quality aerodynamic information can be routinely produced for many engineering applications. The level of success in implementing CFD for solving realistic problems depends on several factors. Obviously, the accuracy of the underlying methodology directly affects the viability of solutions and is of primary importance. Moreover, the robustness of the CFD method and the

\footnotetext{
* Senior Research Engineer, Configuration Aeridynamics Br.

† Senior Research Engineer, Configuration Aerodynamics Br.,

Associate Fellow AIAA

Copyright $\bigcirc 2002$ by the American Institute of Aeronautics and Astronautics, Inc. No copyright is asserted in the United States under Title 17, U.S. Code. The U.S. Government has a royalty-free license to exercise all rights under the copyright claimed herein for Government Purposes. All other rights are reserved by the copyright owner.
}

convenience with which it can be employed determine its productivity for solving realistic problems. The timeliness of generating numerical data is often as significant as accuracy of the solutions, both contributing to the usefulness of the final result. The challenge is especially increased in a design environment where a large amount of data must be generated and analyzed in a short period of time. Therefore, a CFD capability must not only meet the quality requirement of the predicted information but also the practicality and automation with which the data are mass-produced, for example, for generating extensive drag polar and drag rise data.

Although recent years have witnessed many breakthrough advances in the related computational fields, the suitability of CFD methods have not been fully evaluated for many real-world industrial applications. One of the critical challenges of CFD for predicting commercial aircraft performance is the ability of the method to produce reliable drag data. Aerodynamic drag prediction and reduction remains an important (and often formidable) task for the commercial aircraft design to reduce operational costs. While progress in various aspects of CFD are achieved and reported on a regular basis, less attention has been focused on the subject of drag prediction and validating the current CFD methodologies for such applications.

In that regard, a workshop was recently organized by the AIAA Applied Aerodynamics Technical Committee to address the issues related to CFD drag prediction for commercial aircraft design and to evaluate the existing computational capabilities for this purpose. The objective of the workshop was, in particular, to assess the state-ofthe-art computational methods as practical aerodynamic tools for aircraft force and moment computation with emphasis placed on prediction of drag. The workshop was held in conjunction with the $19^{\text {th }}$ AIAA Applied Aerodynamics Conference in Anaheim, CA, 9-10 June 2001 and was attended by several international participants who presented their results on a common wing/body configuration. The workshop provided an impartial forum 
for evaluating the effectiveness of the existing CFD codes as applied to the subject of drag prediction.

The geometry selected for the workshop activity was a subsonic wing/body transport configuration referred to as DLR-F4 model. To maintain as much uniformity among various computations as possible, several baseline multiblock structured, overset, and unstructured grids (similar in resolution) were generated by the workshop organizing committee and provided to the participants to perform their baseline (required) computations. Participants were also encouraged to develop their own grids and apply their best practices to perform additional (optional) cases. The results generated by the participants are included in the workshop proceedings. A summary of the presented data is also given in a companion paper by the workshop organizing committee ${ }^{2}$.

This paper serves as an extended documentation for the baseline unstructured grids provided to the workshop participants and also for one of the participating CFD activities. The paper briefly describes the underlying unstructured grid methodology and presents the results obtained for the DLR-F4 configuration for a range of Mach numbers and angles of attack.

\section{MODEL AND FLOW DESCRIPTION}

As stated in the workshop summary paper ${ }^{2}$, several requirements were considered by the selection committee for choosing an appropriate configuration for the workshop

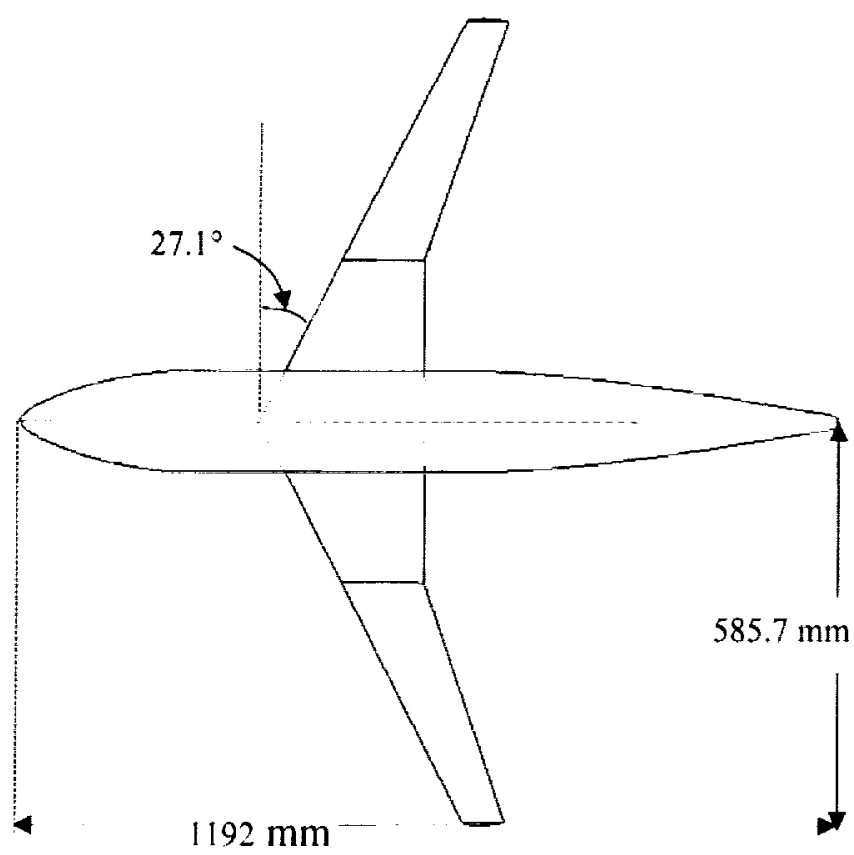

Figure 1. DLR-F4 wing/body geometry (Ref. 3). computational activity. Among the selection criteria, the following were given special consideration: 1) relevancy to the workshop's interest in the transport aircraft design for transonic Might, 2) availability of reliable experimental data, 3) relative geometric simplicity for ease of performing computations by all workshop participants, and 4) nonclassified, non-proprietary requirements. After careful examination of several options, the DLR-F4 wing/body configuration was selected, as it met all of the above conditions. The model has been extensively tested in three different European wind tunnels: ONERA-S2MA, NLRHST, and DRA $-8 \mathrm{ft} \times 8 \mathrm{ft}$ DRA Bedford". It has also been utilized for CFD code validation in Europe ${ }^{4}$. The test results are freely available and, along with the geometry description, are documented in detail in Ref. 3.

The subject geometry consists of a fuselage $1192 \mathrm{~mm}$ long and a swept-back wing of $585.7 \mathrm{~mm}$ semi-span. The wing aspect ratio is 9.5 with a leading-edge sweep angle of 27.1 degrees (see Fig. 1). The wing tip is defined by halfcircular cross-sections with local diameters equal to the corresponding wing thickness values at the tip. The wing body junction is sharp, identified by only the intersection curves (no fillet defined). The body and the wing are numerically specified in Ref. 3 by a number of $x$ and $y$-constant cross sections, respectively. Although geometrically simple, the model resembles a modern transport-type aircraft configuration, which along with extensive experimental data, provides a good candidate data base for CFD code validation.

Using the given numerical sections, the workshop organizing committee constructed a Computer Aided Design (CAD) surface definition by linear lofing between defining sections. The CAD definition was used for generating the baseline CFD grids and also for distribution among the workshop participants. The CAD definition, given in standard Initial Graphics Exchange Specifications (IGES) format, contains 45 surfaces and 4 trim curves shown in Figure 2. For computational economy, a semispan model of the geometry is constructed. The wing

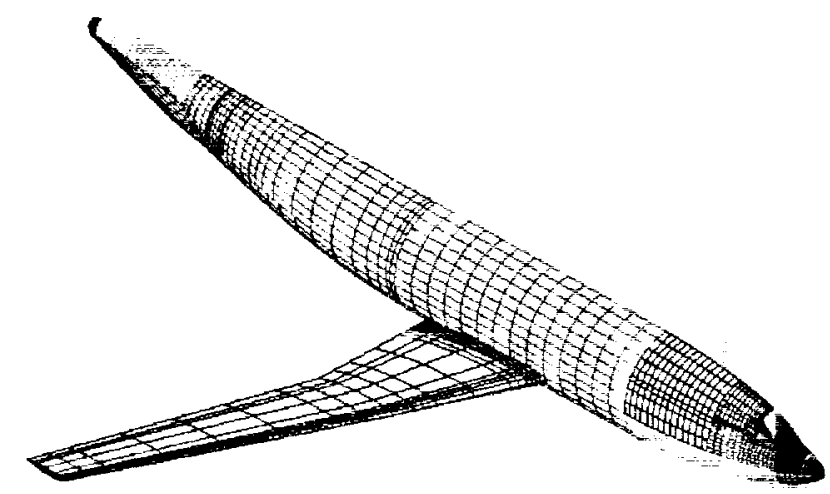

Figure 2. Surface IGES definition for DLR-F4 wing/body geometry. 
surface definition incorporates an aeroelastic deformation under load based on a theoretical estimate for the design condition reported in Ref. 3.

The DLR-F4 model is designed for flying at subsonic through transonic speeds. The dominant cruise flow condition, as observed from the wind tunnel experiments, is primarily attached transonic flow over the wing with pockets of supersonic llow on the upper surlace terminated by weak shock waves. At the design condition, a small separation of flow is observed at the kink region of the wing trailing edge. All experimental data given in Ref. 3 are corrected to "free air" conditions.

\section{COMPUTATIONAL METHOD}

The CFD technique employed for the present computations is based on a tetrahedral unstructured grid methodology. Unstructured grids have gained increasing popularity in the CFD community mainly due to two salient features: 1) the inherent nexibility of the grid elements for discretizing complex domains and 2) the convenience with which the generated grids can be post-processed and modified. While the former reduces the computational cycle time by nearly an order of magnitude for a typical complex configuration, the latter facilitates the implementation of automatic grid adaptation to the flow and/or geometric features.

A coordinated activity has been underway at the NASA Langley Research over the past decade to develop an integrated system of unstructured grid codes. The primary objective of this team effort was to bring the state-of-the-art in CFD to a higher level of usability in the analysis and design environment. The outcome has been a system of user-friendly software referred to as TetrUSS ${ }^{5}$. The system consists of a tetrahedral grid generation package (GridTool and VGRIDns), an Euler and Navier-Stokes solver (USM3Dns), a post-processing analysis code (ViGPLOT), and several other tools and extensions of the codes for solving specific problems. An adaptive grid capability has also been devised recently and is under further development at present time. ${ }^{6}$ Although these codes are often used in combination, the TetrUSS system is modular allowing external unstructured grid codes to be used within the system synergistically.

A brief description of the TetrUSS components is presented below as applied to the DI.R-F4 case for completeness. Further information about the underlying methodology can be found in the respective references.

\section{Grid Generation}

The unstructured grid code VGRIDns generates singleblock, tetrahedral grids for both Euler and Navier-Stokes computations. The grid generation method is based on the Advancing-front ${ }^{7}$ and the Advancing-layers ${ }^{8}$ techniques. Both techniques resemble marching procedures by which tetrahedral cells grow in the computational field from a triangular surface mesh (initial front). The advancing process continues until the entire domain is filled with contiguous tetrahedral cells. The advancing-front technique inserts individual cells in the inviscid portion of the flow field in an irregular fashion. The lack of an apparent order in which the grid is generated contributes to the flexibility of the method. On the contrary, the advancing-layers method generates thin layers of tetrahedral cells packed in the boundary-layer region in a more orderly manner. Each advancing layer contains a stack of three tetrahedral cells. The systematic way of generating grids by the advancinglayers method is favored for the ease of generation and better quality of thin tetrahedral cells in the boundary layer.

The generation of a surface mesh is accomplished in two main steps: 1) geometry set-up and preparation of grid parameters, both using the graphical grid utility code GridTool $^{9}$ and 2) surface triangulation with VGRIDns. The geometry of interest is tirst defined in terms of a set of bilinear parametric and/or Non-Uniform Rational B-Spline (NURBS) patches using the given CAD surface definition. The surface patches are constructed with GridTool interactively. The union of all these contiguous patches (including those defining the outer boundaries) forms a "water-tight" surface enclosing the entire computational domain. Figure 3 shows a surface patch representation of the DLR-F4 model for generating unstruclured grids with VGRIDns. In this example, the model, along with a rectangular outer boundary (not shown), is defined in terms of 106 bi-linear parametric and NURBS patches.

The distribution of the unstructured grid points on the surface and in the field is accomplished with VGRIDns by means of a set of user-prescribed source elements. These sources are also defined and placed in the domain using GridTool. The source elements, along with a "transparent" background grid ${ }^{11}$ (on which the source information is distributed by solving a Poisson equation), provide the required data for generating the final unstructured grid.

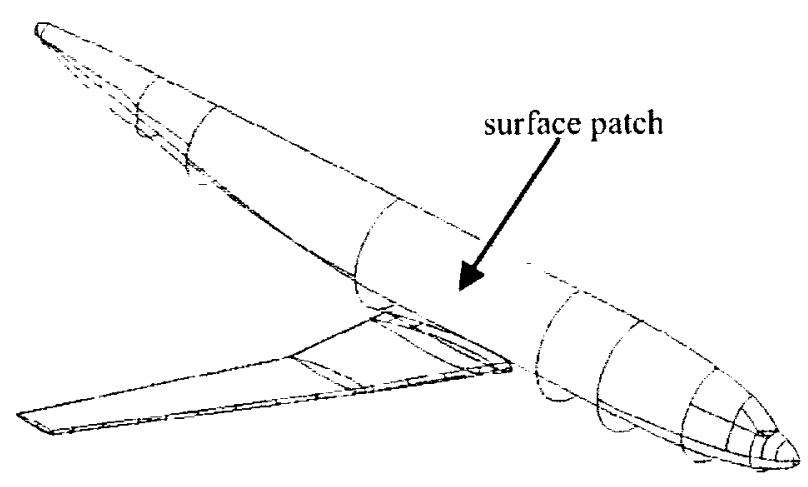

Figure 3. Surface patch representation of the DLR-F4 model. 


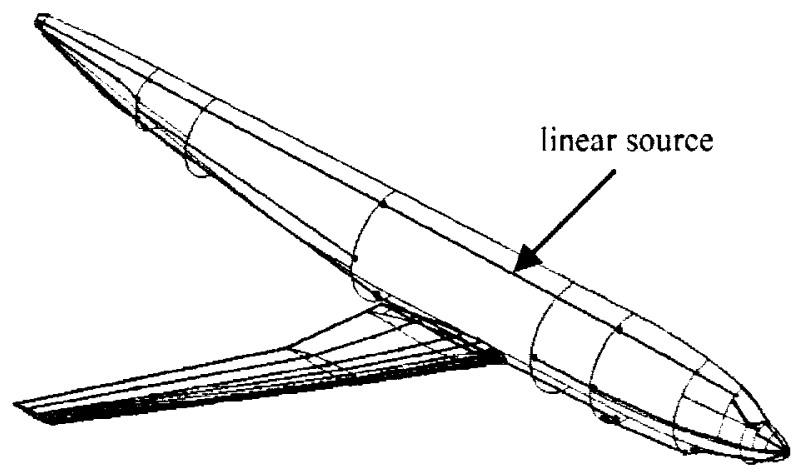

Figure 4. Arrangement of source elements on DLRF4 for grid clustering.

Figure 4 illustrates several "linear" source elements placed in the DLR-F4 fuselage and wing for controlling the grid clustering on and around the geometry.

The process of preparing surface patches and grid distribution parameters constitutes $50-90 \%$ of the total grid generation time depending on the complexity of the geometry and the "cleanliness" of the CAD surface definition. In any grid generation method, a substantial amount of time and effort is often spent to repair faulty or incomplete $C A D$ surface definitions before the actual process of grid generation starts. For the present problem, the surface geometry was well defined, allowing the surface patches to be constructed easily in approximately one hour. The complete first grid, from CAD to the final postprocessed volume grid, was generated in one day on a Silicon Graphics (SGI) workstation. Additional iterations were required to modify source parameters to fit the final grid with the desired characteristics (such as size, local resolution, stretching, etc.) prescribed by the committee for the workshop computations.

Once the surface patches and sources are in place, the surface mesh is generated automatically with VGRIDns. In VGRIDns, individual surface patches are triangulated using the two-dimensional (2D) versions of the advancing-front and advancing-layers methods. Additionally, a recent modification of the code allows triangulation of the NURBS surfaces in the 3D space. The new capability provides for better quality surface grids, guarantees the grid nodes to stay on the CAD surface, and accepts surface patches of arbitrary shapes and number of edges (a substantial simplification of the patching process). The capability of direct surface triangulation on NURBS surfaces is still under further development and is not available in the current (released) version of VGRIDns.

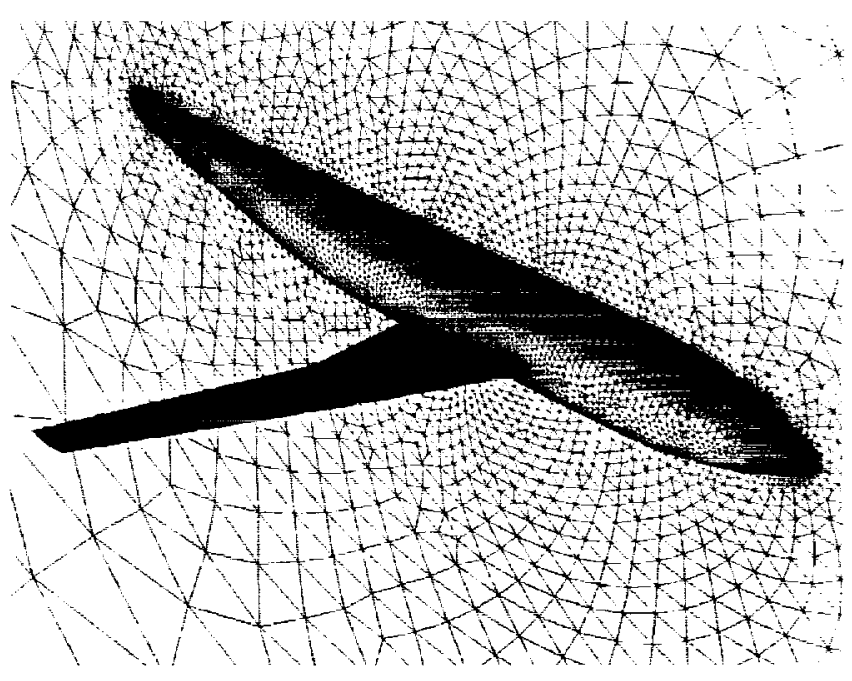

Figure 5. Surface triangulation on the DLR-F4 model and the plane of symmetry.

A collection of all triangulated surface patches makes up the final surface mesh that also acts as an initial front for generating the tetrahedral volume grid by the advancingfrontlayers methods. Figure 5 shows the surface triangulation on the DLR-F4 model as well as the grid on the symmetry plane.

A salient feature of VGRIDns is a multi-directional, anisotropic grid clustering capability, by which grid points can be distributed nonuniformly in different directions, producing stretched grid elements. The result is a reduction of total cell count by a factor of three without losing the grid resolution in the essential directions. For the present problem, grid stretching is mainly applied at the wing leading and trailing edges in the spanwise direction while maintaining high concentration of grid nodes chordwise (see Fig. 6).

As mentioned earlier, the generation of tetrahedral volume grid is achieved with the $3 D$ versions of the marching techniques, similar to those utilized for surface triangulation. After the process of volume grid generation with VGRIDns is over, some voids may remain in the inviscid portion of the grid which cannot be closed with the grid generator itself. Furthermore, the generated grid usually contains isolated pockets of distorted cells, which may be unacceptable to some solvers. The inherent irregularity of unstructured grids not only provides ease of generation but also offers flexibility for alteration and postprocessing of the generated grids. Any segment of a tetrahedral grid can be removed and locally re-meshed without disturbing the rest of the grid. This operation is performed with a computer program referred to as POSTGRID $^{11}$ as the last stage of the generation process. 


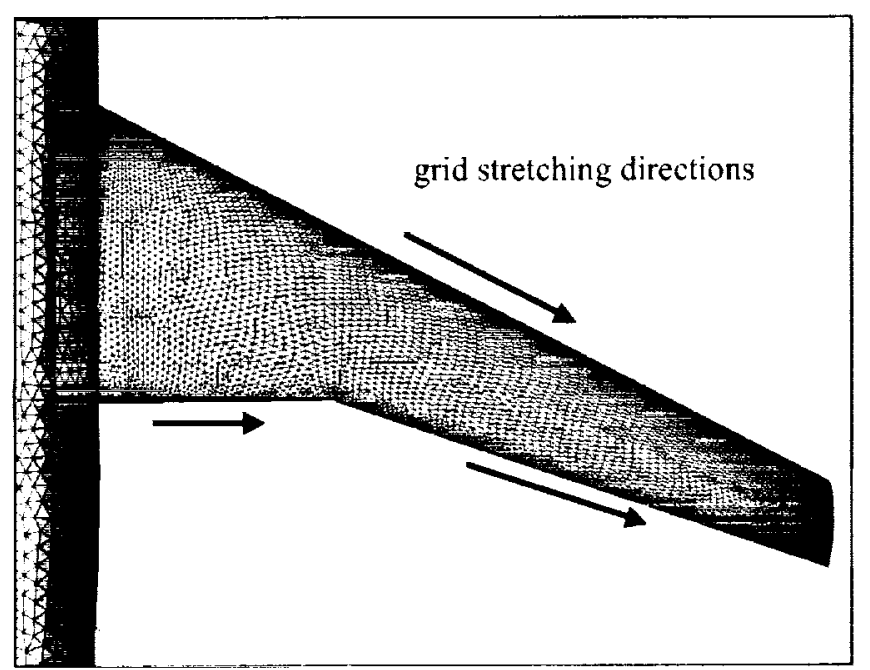

(1)

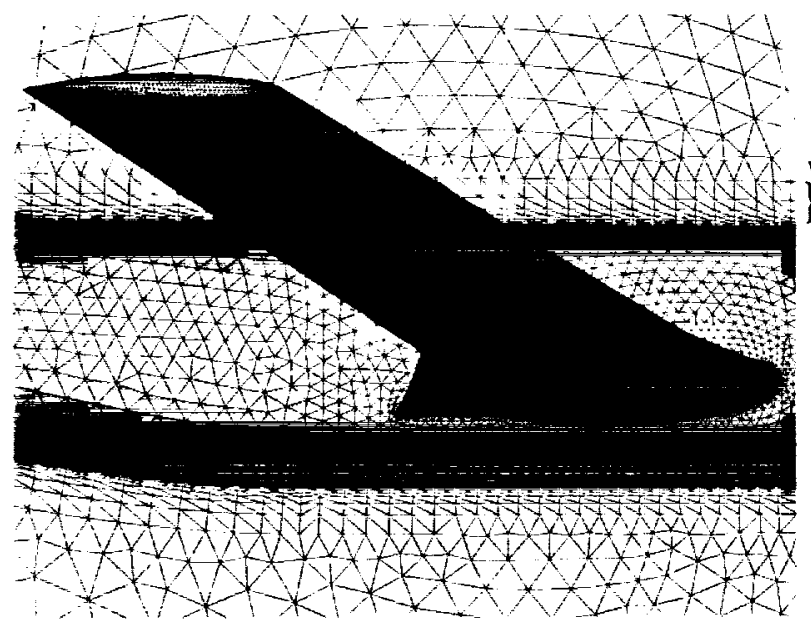

(c)

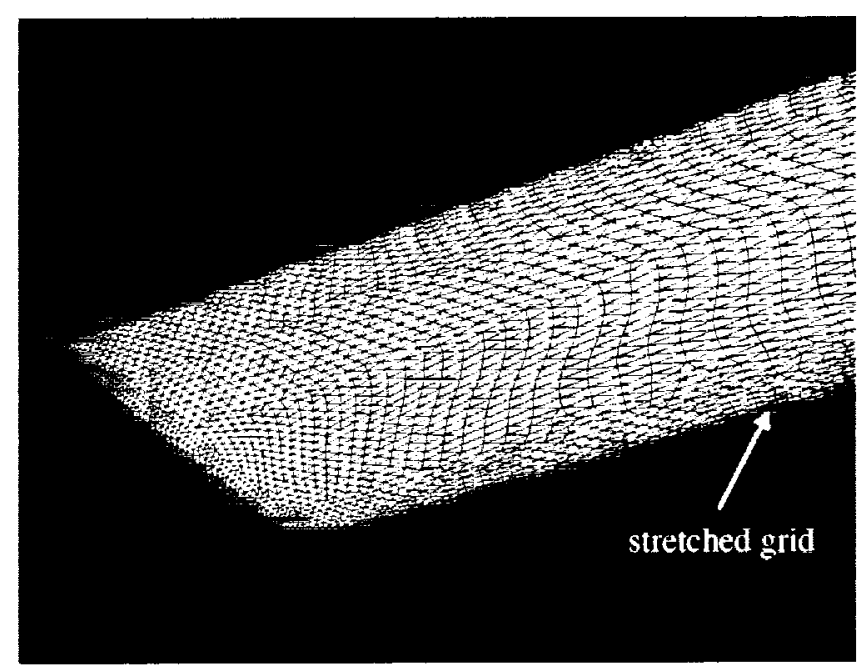

(b)

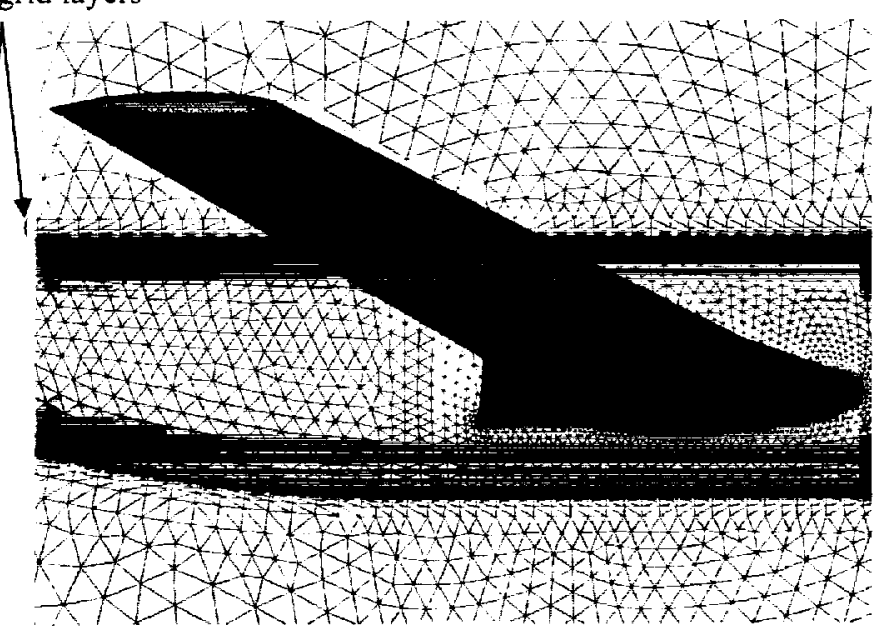

(d)

Figure 6. Details of surface grid on the DLR-F4 model: (a) wing upper surface showing stretched grid in spanwise direction (b) variable stretching in the wing tip and leading edge region, (c) "fullviscous" grid with 35 viscous layers, and (d) "wall-function" grid with 12 viscous layers.

\section{Flow Solution}

USM3Dns is a tetrahedral cell-centered, finite volume Euler and Navier-Stokes solver ${ }^{2}$. The inviscid flux quantities are computed across the cell faces using the Roe's flux-difference splitting scheme, and the spatial discretization is accomplished by a novel analytical reconstruction process. The solution is advanced in time to steady state using an implicit backward-Euler time-stepping scheme. Flow turbulence is modeled by the SpalartAllmaras one-equation model, which is optionally coupled with a wall function to reduce solution stiffness and the number of cells in the sublayer of the boundary layer. All computations presented in this paper are performed using the wall-function feature of USM3Dns in a fully turbulent mode.

USM3Dns runs on massively parallel computers and clusters of personal computers (PC's). A single processor version is available for vector processors, such as the Cray super-computers, with multi-tasking, and single workstations. The parallel version ${ }^{13,14}$ is the version of choice because it enables rapid turnaround of large problems. The code requires 175 eight-bit words of memory per tetrahedron. It runs with a speed of 34 $\mu \mathrm{sec} / \mathrm{cell} / \mathrm{cycle} / \mathrm{processor}$ on a Cray C90 and 230 $\mu \mathrm{sec} / \mathrm{cell} / \mathrm{cycle}$ /processor on the SGI Origin 2000 parallel computer.

USM3Dns supports standard boundary conditions such as the flow tangency, no-slip solid surface, characteristic 
inflow/outflow (for subsonic flows), and freestreaminllow/extrapolation-outflow (for supersonic llows). In addition, some special boundary conditions including wall functions, wake flow, jet engine, and propeller are available in the code, and are reviewed in Ref. 5.

\section{RESULTS}

\section{Tetrahedral Grids for Workshop}

For the required workshop CFD computations, three unstructured grids were generated on the DLR-F4 wingbody configuration and distributed among the workshop participants. Table 1 contains the specifications of these grids. While the basic characteristics of the grids (e.g., "effective" resolutions) are comparable around the geometry, each grid has been generated for a specific solution strategy. Because tetrahedral unstruclured grids contain 5-6 times more cells than nodes, a grid of sufficient density for a cell-centered solver is usually considered too coarse for a solution technique utilizing a node-based scheme. In addition, solvers employing analytical wall functions to approximate flow in the viscous sublayer require fewer grid elements across the boundary layer compared to those solving the Navier-Stokes equations to the surface.

The distributions of grid spacing normal to the wall were prescribed uniformly over the entire geometry. The nominal normal spacings were determined at the mid-span,

\begin{tabular}{|c|c|c|c|}
\hline \multirow{2}{*}{ Grid Characteristics } & \multirow{2}{*}{$\begin{array}{l}\text { Node-based Grid } \\
\text { (Full Viscous) }\end{array}$} & \multicolumn{2}{|c|}{ Cell-based Grid } \\
\hline & & Full Viscous & Wall-function \\
\hline Boundary points & 48,339 & 23,290 & 25,175 \\
\hline Surface triangles & 96,674 & 46,576 & 50,346 \\
\hline Triangles on no-slip surfaces & 72,902 & 30,037 & 38,571 \\
\hline Total grid points & $1,647,810$ & 470,427 & 414,347 \\
\hline Points in viscous layers & $1,129,427$ & 389,753 & 238,301 \\
\hline Total tetrahedral cells & $9,686,802$ & $2,743,386$ & $2,390,089$ \\
\hline Cells in advancing (viscous) layers & $6,495,828$ & $2,208,260$ & $1,281,854$ \\
\hline Maximum number of viscous layers & 35 & 35 & 12 \\
\hline Number of complete viscous layers & 24 & 24 & 7 \\
\hline Grid points across wing T.E. & 5 & 5 & 5 \\
\hline Chordwise grid spacing at L.E. & $\sim 0.250 \mathrm{~mm}$ & $\sim 0.450 \mathrm{~mm}$ & $-0.450 \mathrm{~mm}$ \\
\hline Chordwise grid spacing at T.E. & $\sim 0.500 \mathrm{~mm}$ & $-0.800 \mathrm{~mm}$ & $-0.800 \mathrm{~mm}$ \\
\hline Maximum spanwise spacing at L.E & $\sim 2.500 \mathrm{~mm}$ & $\sim 6.000 \mathrm{~mm}$ & $-6.000 \mathrm{~mm}$ \\
\hline Maximum spanwise spacing at T.E & $\sim 3.500 \mathrm{~mm}$ & $\sim 3.500 \mathrm{~mm}$ & $-3.500 \mathrm{~mm}$ \\
\hline Grid spacing on the fuselage & $-10.000 \mathrm{~mm}$ & $-10.000 \mathrm{~mm}$ & $-10.00 \mathrm{~mm}$ \\
\hline Grid spacing at the outer boundary & $\sim 3000.000 \mathrm{~mm}$ & $\sim 3000.000 \mathrm{~mm}$ & $-3000.000 \mathrm{~mm}$ \\
\hline First "viscous" spacing off the wall & $0.001 \mathrm{~mm}$ & $0.003 \mathrm{~mm}$ & $0.0549 \mathrm{~mm}$ \\
\hline $\begin{array}{l}\text { Rate of geometric stretching } \\
\text { (viscous layers) }\end{array}$ & $\sim 1.2$ & -1.2 & Eq. (1) \\
\hline Outer boundary box size & 50 mean chords & 50 mean chords & 50 mean chords \\
\hline
\end{tabular}

Table 1. Grid specifications for three different unstructured grids generated for the DLR-F4 Drag Prediction Workshop. 
mid-chord location on the wing using flat-plate turbulent boundary layer theory. For the "wall-function" grid, an initial spacing for $y^{+}$of 50 was assumed, whereas those of the "full viscous" Navier-Stokes grids were set to provide a $y^{+}$of 1 . For the full Navier-Stokes grids, a geometric stretching factor of 1.2 was applied. For the wall-function grid, the clustering of points normal to the surface was computed according the stretching function

$$
\delta_{n}=\delta_{1}\left[1+a(1+b)^{n-1}\right]^{n-1}
$$

where $\delta_{n}$ is the normal spacing of the $n^{\text {th }}$ layer. $\delta_{1}$ is the first layer spacing prescribed by the user, and the factors $a$ and $b$ are constants that determine the rate of stretching, also prescribed by the user. For the current wall-function grid, the parameters $\delta_{1}, a$, and $b$ have been set to $0.0549 \mathrm{~mm}$, 0.37 and 0.07 , respectively, which have produced approximately 18 tetrahedral cell layers (6 nodal layers) across the mid-chord boundary layer.

Figure 6 illustrates some details of the surface triangulation, including the "full viscous" and the "wallfunction" grids. The smooth clustering of surface triangulation is evident on the wing and fuselage. Note also the spanwise stretching of the grid along the leading edge in Fig. $6(\mathrm{~b})$ that reduces the overall number of cells considerably. Figures $6(\mathrm{c})$ and $6(\mathrm{~d})$ illustrate the respective extents of the advancing (viscous) layers for the "full viscous" and "wall function" grids.

The provided CAD representation of the DLR-F4 model has a wing with a blunt trailing edge definition. The trailing edge is resolved on the present grids by five grid nodes. Wing trailing edge condition (sharp vs. blunt) has been known to have influence on location of the upstream shock waves and, thus, on the computed drag counts. The effect of wing trailing edge on the drag prediction and issues regarding the grid resolution at this location are among the subjects requiring further in-depth investigations. The present grids are restricted to an underlying O-type topology that limits the attainable resolution of the trailing-edge wake region. Automatic grid adaptation (currently under development) would further facilitate the study of grid sensitivity and its effect on solution accuracy.

\section{USM3Dns Flow Solutions}

Flow solutions were computed on the DLR-F4 configuration with USM3Dns for the conditions shown in Table 2 as recommended by the workshop organizing committee. All cases are at a Reynolds number of $3.0 \times 10^{8}$ based on the mean aerodynamic chord (mac). Cases 1 and 2 were designated as "required" computations by all participants. The participants were also required to use the workshop-provided grids for Case 1. However, they were encouraged to generate their own computational grids or, if desired, use the provided grids for the remaining cases. Computations for Cases 3 and 4 were optional. An additional case was computed with USM3Dns for $\mathrm{M}_{x}=$ $0.75, \alpha=0.93 \mathrm{deg}$., and $\operatorname{Re}_{\operatorname{mac}}=3.0 \times 10^{6}$ to initially evaluate

\begin{tabular}{|c|c|c|c|}
\hline Case & $\mathbf{M}_{\infty}$ & $\alpha, \mathrm{deg}$. & $\mathrm{C}_{\mathrm{L}}( \pm 0.001)$ \\
\hline $\begin{array}{c}\text { 1) Single } \\
\text { point }\end{array}$ & 0.75 & -- & 0.5 \\
\hline 2) Drag & & $-3.0,-2.0$, & \\
polar & 0.75 & $\begin{array}{c}-1.0,0.0, \\
1.0,2.0\end{array}$ & -- \\
\hline & & & \\
3) Mach & $0.70,0.60$, & & 0.5 \\
sweep & $0.76,0.77$, & & \\
& $0.78,0.80$ & & \\
\hline & $0.50,0.60$, & & 0.40, \\
4) Drag & $0.70,0.75$, & & $0.50,0.60$ \\
rise & $0.76,0.77$, & & \\
& $0.78,0.80$ & & \\
\hline
\end{tabular}

Table 2. Workshop flow cases for the DLR-F4 configuration at $\operatorname{Re}_{\operatorname{mac}}=3.0 \times 10^{6}$

the code perfonnance and assess preliminary comparisons with Ref 4. All workshop computations assumed fully turbulent flow, whereas the experimental data utilized a fixed transition technique to trip the flow from laminar to turbulent near the leading edge.

Boundary conditions for the USM3Dns solutions consisted of a mirroring condition for the symmetry plane, characteristic inflow/outllow for the outer boundaries, a wall function on all aerodynamic surfaces with an exception of the wing trailing edge. The thick trailing edge surface was treated by a special "wake" artifice" that was developed to mimic the relieving effect of a blunt-base wake on a coarse grid. This formulation introduces a solution-defined transpiration velocity on the blunt-base boundary faces to provide a smooth departure of the flow past the comer. This boundary condition has been tested and is used extensively with inviscid flows and wall function applications.

The USM3Dns flow solutions were converged to at least 4-orders of magnitude residual reduction which required between 2000 and 5000 iterations, depending on the extent of flow separation. All solutions were generated with no difficulty. Each flow condition required between 1.7 and 4.2 wallclock hours to run on 48 processors of the NASA Origin 2000 National Aerospace Simulator (NAS) computer.

Figure 7 portrays the surface pressure coefficient contours on the wing upper surface for the initial solution. At the flow condition $M_{\infty}=0.75, \alpha=0.93 \mathrm{deg}$., the surface pressures show a classic transonic shock formation with an inboard lambda compression region that is consistent with the CFD and experimental data reported in Ref. 4. 
Figure 8 depicts a small vortex separation at the trailing edge wing/fuselage junction. Ref. 4 notes the experimental and computational presence of this feature that is expected to have some effect on total drag. It is noteworthy that the wall function does not impede the formation of such threedimensional flow separations.

\section{Effect of Flux Limiter}

During the analysis of the initial flow solution, the lift and drag coefficients appeared high compared to the experimental result in Ref. 4 , as observed in the first two rows of Table 3. Other users of the code have also observed this tendency with similar configurations in the past. After some additional exploratory calculations, the minmod flux limiter was isolated as the cause. As evident in Table 3, turning off the limiter resulted in a 48 -count reduction in total drag and a 30 -count increase in lift coefficient.

Flux limiters are routinely used in upwind schemes to prevent numerical overshoots in pressure just ahead of shock waves. Figure 9 portrays the effect of the limiter on predicted surface pressure coefficients $(C p)$ in comparison with experimental data at six span stations on the wing. In general the flux limiter has little effect in altering shock location, but both tend to predict the shock location slightly aft. Note also that the unlimited solution exhibits no sign of an overshoot of $C p$ near the shock, suggesting that the limiter is not needed for this application. While the effect of the limiter on the $C p$ distributions appears insignificant, the drag differs by 48 counts. Close observation of Fig. 9 reveals that the limited solution (solid line) has slightly more positive $C p$ at the leading-edge suction peak, and slightly more negative $C p$ on the aft-wing upper surface than that for the unlimited solution (dashed line). One can infer that a higher pressure acting on the forward-facing leading edge surface, and lower pressure acting on the aftfacing aft-wing upper surface will each contribute a positive axial component to pressure drag. Thus the subsequent solutions for the workshop cases have been run without a flux limiter due to this unresolved issue.

\begin{tabular}{|c|c|c|}
\hline Data & $\mathrm{C}_{\mathrm{L}}$ & $\mathrm{C}_{\mathrm{D}}$ \\
\hline Experiment (Ref. 4) & 0.602 & 0.0352 \\
\hline $\begin{array}{c}\text { USM3Dns } \\
\text { (with limiter) }\end{array}$ & 0.650 & 0.0412 \\
\hline $\begin{array}{l}\text { USM3Sns } \\
\text { (no limiter) }\end{array}$ & 0.653 & 0.0364 \\
\hline
\end{tabular}

Table 3. Lift and drag coefficients for DLR-F4 model. $M_{\alpha}=0.75, \alpha=0.93^{\circ}$, and $\operatorname{Re}_{\operatorname{mac}}=3.0 \times 10^{6}$.

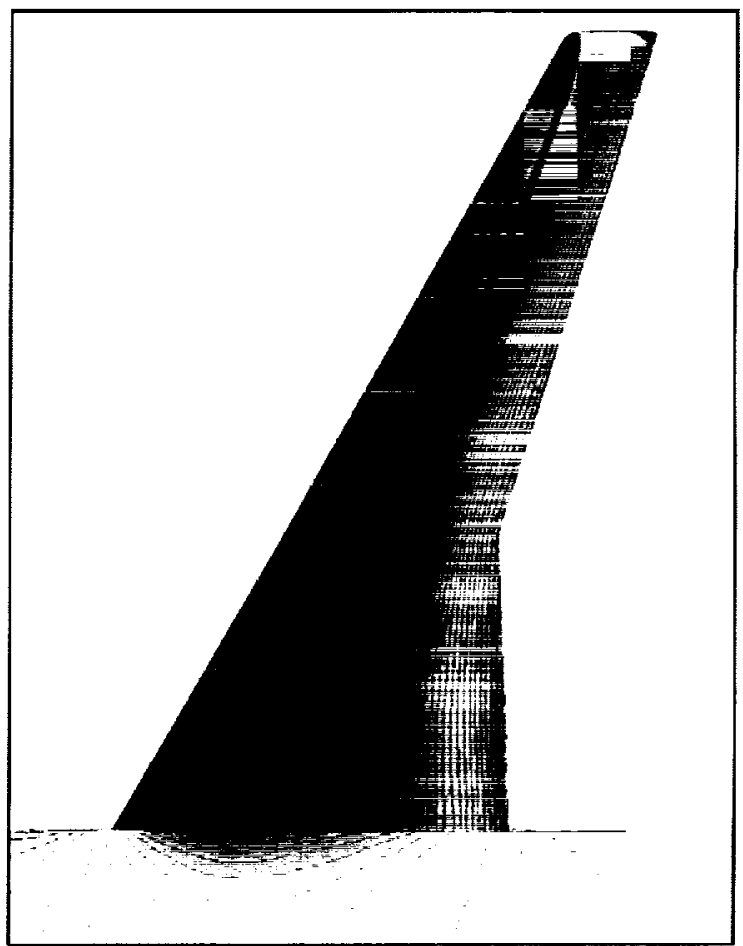

Figure 7. Surface pressure coefficient contours on DLR-F4 wing, $M_{x}=0.75, \alpha=0.93^{\circ}$, $\operatorname{Re}_{\operatorname{mac}}=3.0 \times 10^{6}$. (Magenta - low pressure, Green - high pressure).

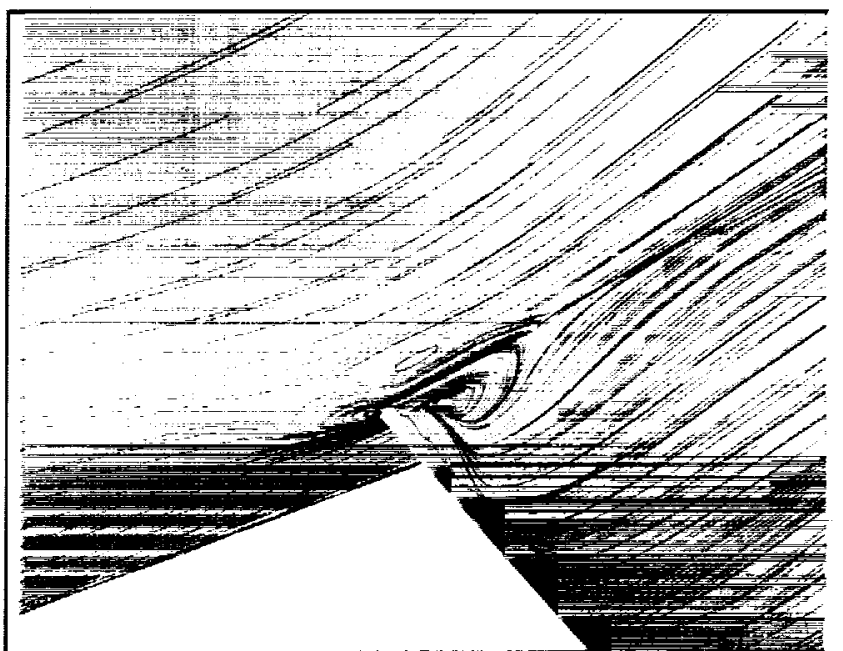

Figure 8. Predicted oil flow traces on the DLR-F4 configuration showing footprint of a vortex separation at wing-body junction. 

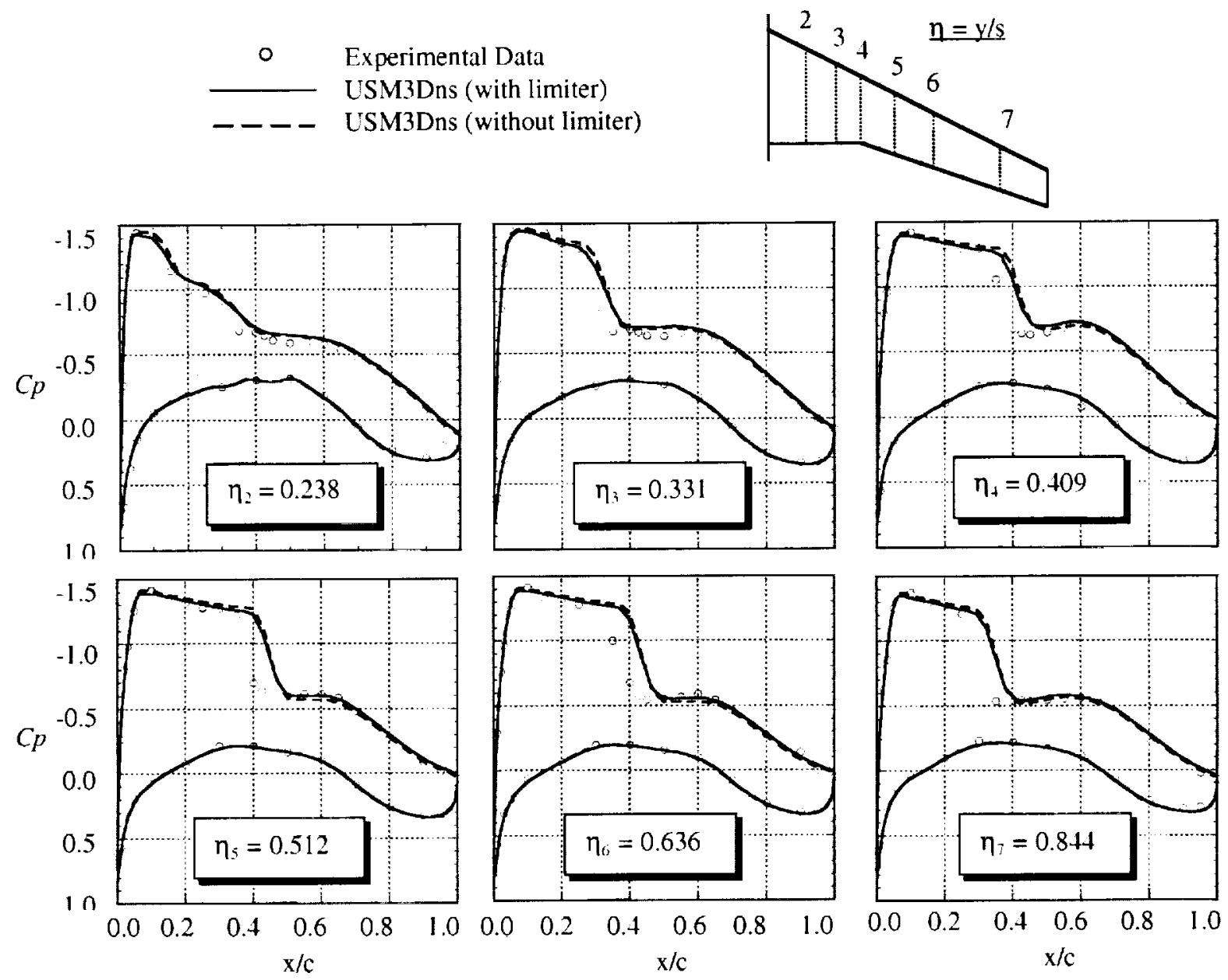

Figure 9. Effect of nux limiter on surface pressure distributions on DLR-F4 wing. $M_{\infty}=0.75$, $\alpha=0.93^{\circ}$, and $\operatorname{Re}_{\max }=3.0 \times 10^{6}$.

\section{Statiștical Comparison}

A robust statistical evaluation of 35 CFD solutions presented in the Drag Prediction Workshop has been compiled by Hemsch in Ref. 16. These solutions were generated from a range of structured and unstructured Navier-Stokes flow codes, with one- and two-equations turbulence models, and from different users. Thus, the current statistical analysis serves as an initial baseline to assess solution accuracy of an individual code relative to a larger population.

The statistical limits to be used in Tables 4 to 7 were extracted from Ref. 16. These tolerances generally express the statistical probability that an individual solution would fall outside these limits more than one time in 100 in the long run by chance ( $99 \%$ coverage).

The first workshop flow Case 1 is a single point computation at $\mathrm{M}_{\infty}=0.75, \mathrm{C}_{\mathrm{L}}=0.5$, and $\mathrm{Re}_{\mathrm{mac}}=3.0 \times 10^{6}$. Table 4 displays the lift, drag, and pitching moment coefficients for two USM3Dns results and from three different wind tunnels. A statistical composite of the windtunnel data is included from Ref. 16 to convey the scatter in the data. The electronic data tables that provided the wind tunnel coefficients were furnished to an accuracy of 10 counts. For the purposes of the workshop, the round-off error was reduced considerably by use of an interpolation technique developed by Vassberg. The USM3Dns flow computations were performed at a constant $C_{L}$ of 0.5 using an automated feedback loop in the code that adjusted angle of attack to $-0.300 \mathrm{deg}$. In addition, solutions were obtained at an averaged angle of attack corresponding to $C_{L}=0.5$ from the three wind tunnel tests $\left(\alpha_{\mathrm{avg}}=0.175 \mathrm{deg}\right.$. $)$. The difference of the USM3Dns point result in Table 4 from the mean value of the workshop CFD solutions is enclosed within parenthesis. While the variation for the computed drag coefficient at "constant $C_{\mathrm{L}}$ " $(-0.0009)$ is only 1 count outside of the experimental scatter $( \pm 0.0008)$, the angle of attack and pitching moment coefficient are significantly farther outside their respective ranges.

More understanding of these differences can be derived from the $C p$ comparisons in Figure 10. Shown is a comparison of the two computational solutions in Table 4 
with the three sets of experimental data at six span stations. When $C_{L}$ is matched between USM3Dns and experiment by varying angle of attack (solid line), the distributions differ considerably, while the integrated lift is the same. Similarly, if an averaged angle of attack is used (dashed line), the general agreement with experiment is better ahead of the shock, but the shock position is too far aft, and lift and drag are higher. Similar mismatch of the predicted surface pressures was experienced by most of the other workshop participants as well. The many reasons offered at the workshop for these differences concerned offsets in angle of attack, wind tunnel walls and blockage effects, sting effects, aeroelastic effects, and the influence of the wing trailing-edge bluntness on the upstream flow. More discussion on this matter is available in Ref. 2. As a general rule, these comparisons suggest that the experimental data set should only be considered as a guide in this study due to the number of issues clouding the correlations. The more useful focus of our assessment should be on comparisons to the statistical composite of CFD solutions from the Drag Prediction Workshop.

A comparison of predicted drag from USM3Dns to the larger population of CFD codes is presented in Table 5, and similarly in Table 6 for angle of attack and pitching moment. The total drag estimate in Table 5 is within 17 percent of the scatter of the larger population of codes. Angle of attack in Table 6 is within 12-percent and pitching moment within 9-percent. These results confirm that the accuracy for predicting drag and other aerodynamic parameters at transonic cruise conditions using a tetrahedral cell-centered scheme coupled with a wall function is well within the scatter band of other structured and unstructured codes solving the Navier-Stokes equations to the wall.

Case 2 designates a drag polar prediction at $\mathrm{M}_{\infty}=0.75$ and six angles of attack: $-3,-2,-1,0,1$, and 2 degrees. Plots of angle of attack vs. lift, drag vs. lift, and lift vs. pitching moment coefficients are presented in Figure 11. There is a good consistency among the lift and drag measurements in three different wind tunnels. While the computational $C_{D}$ vs. $C_{L}$ curve matches the experimental data fairly well, the lift coefficients are generally overpredicted at individual angles of attack. The slope of the $\alpha$ vs. $C_{L}$ curve, however, matches those of the experiments reasonably well before it breaks downward prematurely at higher incidence. As illustrated in Fig. 11, the entire predicted $\alpha$ vs. $C_{L}$ curve appears to lag the experiments by an incidence offset of about one-half degree. Similar over prediction of the lin has been observed from the majority of workshop computations. As stated in Ref. 2, an average offset of 0.414 degree was required to achieve the target $C_{L}$ by all computations.

Unlike the force measurements, the experimental pitching moments in Fig. 11 exhibit a larger disparity (at the scale presented), and the computational results are generally under-predicted (nose-down). While the exact source of inaccuracy is not known, several factors are believed to have contributed to the mismatch. Among those suggested in Ref. 2 are the free-air assumption for computations, absence of the sting mount in the CFD

\begin{tabular}{ccccc}
\hline Data & $\begin{array}{c}\alpha \\
\text { (deg.) }\end{array}$ & $\mathrm{CL}$ & $\begin{array}{c}\mathrm{CD} \\
\text { (Interpolated) }\end{array}$ & $\mathrm{CM}$ \\
\hline ONERA & 0.192 & 0.50 & 0.0289 & -0.126 \\
NLR & 0.153 & 0.50 & 0.0288 & -0.130 \\
DRA & 0.181 & 0.50 & 0.0281 & -0.137 \\
\hline Statistical & 0.18 & 0.50 & 0.0286 & -0.130 \\
Composite & \pm 0.04 & & \pm 0.0008 & \pm 0.01 \\
\hline USM3Dns & -0.300 & $\mathbf{0 . 5 0}$ & 0.0277 & -0.158 \\
(constant $\left.C_{\mathrm{L}}\right)$ & $(-0.48)$ & $\underline{(-0.0009)}$ & $(-0.028)$ \\
USM3Dns & $\underline{\mathbf{0 . 1 7 5}}$ & 0.56 & 0.0303 & -0.156 \\
(constant $\alpha)$ & $\underline{(-0.005)}$ & $(+0.06)$ & $(0.0017)$ & $(-0.026)$ \\
\hline
\end{tabular}

Table 4. Forces and moment data for Case 1 DLR-F4.

\begin{tabular}{|c|c|c|c|c|}
\hline & & $\begin{array}{c}C_{D} \\
\text { pressure }\end{array}$ & $\begin{array}{c}C_{D} \\
\text { Skin } \\
\text { Friction }\end{array}$ & $\begin{array}{c}C_{D} \\
\text { Total }\end{array}$ \\
\hline \multirow{2}{*}{ 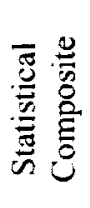 } & Experiment & -- & -- & $\begin{array}{c}0.0286 \\
\pm 0.0008\end{array}$ \\
\hline & $\begin{array}{c}\text { Workshop } \\
\text { Case } 1\end{array}$ & $\begin{array}{c}0.0166 \\
\pm 0.0036\end{array}$ & $\begin{array}{c}0.0134 \\
\pm 0.0039\end{array}$ & $\begin{array}{c}0.0293 \\
\pm 0.0054\end{array}$ \\
\hline 导吾 & $\begin{array}{c}\text { USM3Dns } \\
\text { Case l }\end{array}$ & $\begin{array}{c}0.0159 \\
(-0.0007)\end{array}$ & $\begin{array}{c}0.0118 \\
(-0.0016)\end{array}$ & $\begin{array}{c}0.0277 \\
(-0.0009)\end{array}$ \\
\hline
\end{tabular}

Table 5. Comparison of USM3Dns drag prediction to statistical data ${ }^{16}$.

\begin{tabular}{|c|c|c|c|}
\hline & & $\alpha$, deg. & $\mathrm{C}_{\mathrm{M}}$ \\
\hline \multirow{2}{*}{ 苞 } & Experiment & $0.18 \pm 0.04$ & $-0.13 \pm 0.01$ \\
\hline & $\begin{array}{c}\text { Workshop } \\
\text { Case } 1\end{array}$ & $-0.26 \pm 0.34$ & $-0.160 \pm 0.0217$ \\
\hline 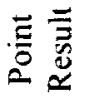 & $\begin{array}{c}\text { USM3Dns } \\
\text { Casel }\end{array}$ & $\begin{array}{l}-0.300 \\
(-0.04)\end{array}$ & $\begin{array}{c}-0.1581 \\
(0.0019)\end{array}$ \\
\hline
\end{tabular}

Table 6. Comparison of LSM3Dns angle of attack and pitching moment to statistical data ${ }^{16}$. 

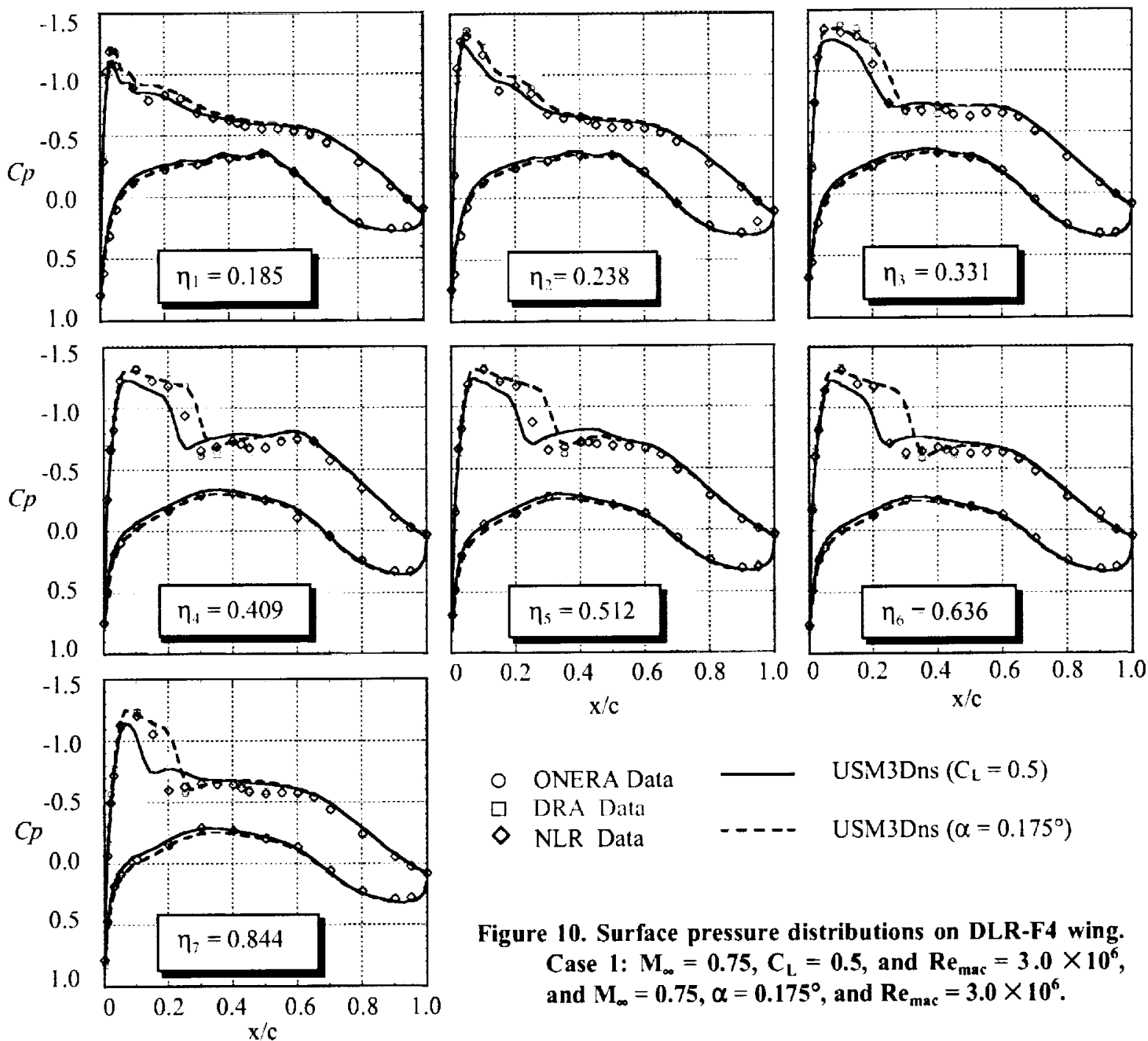

Figure 10. Surface pressure distributions on DLR-F4 wing. Case 1: $M_{\infty}=0.75, C_{L}=0.5$, and $\operatorname{Re}_{\text {mac }}=3.0 \times 10^{6}$, and $M_{\infty}=0.75, \alpha=0.175^{\circ}$, and $\operatorname{Re}_{\operatorname{mac}}=3.0 \times 10^{6}$.

model, aeroelastic effects under load, and the absence of a tail that affects stability of the model. Although the experimental data have been corrected to free-air and the CFD model adjusted for aeroelastic effects, these corrections are believed to be crude and may have been inadequate to warrant similar conditions for the experiments and computations. The nose-up break in the pitching moment is slightly premature as noted for the lift coefficient. This result is unfortunate, but not surprising because of the many factors ciled in Ref. 2 .

Several polar related slope parameters, such as liftcurve slope $\left(\mathrm{C}_{\mathrm{L}, \alpha}\right)$, lift at zero angle of attack $\left(\mathrm{C}_{\mathrm{L}, 0}\right)$, drag at zero lift $\left(C_{D} @ C_{1}=0\right)$, and span efficiency factor, $\left(\mathrm{k}=\left(\mathrm{C}_{\mathrm{D}}-\mathrm{C}_{\mathrm{D}}\left(\mathrm{C}_{\mathrm{L}}=0\right) /\left(\mathrm{C}_{\mathrm{L}}\right)^{2}\right)\right.$ are compared against workshop CFD results in Table 7 . The difference of the USM3Dns point result in Table 7 from the mean value of the workshop CFD solutions is enclosed within parenthesis. The USM3Dns results are well within the scatter for each of

\begin{tabular}{|c|c|c|c|c|c|}
\hline & & $C_{L, \alpha}$ & $C_{L, 0}$ & $\begin{array}{l}\mathrm{C}_{\mathrm{D}} @ \\
\mathrm{C}_{\mathrm{L}}=0\end{array}$ & k \\
\hline \multirow{2}{*}{ 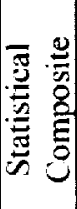 } & Expt & $\begin{array}{c}0.114 \\
\pm 0.0038\end{array}$ & $\begin{array}{c}0.473 \\
\pm 0.006\end{array}$ & $\begin{array}{c}0.0188 \\
\pm 0.0010\end{array}$ & $\begin{array}{c}0.0374 \\
\pm 0.0080\end{array}$ \\
\hline & $\begin{array}{l}\text { Wkshp } \\
\text { Case2 }\end{array}$ & $\begin{array}{c}0.120 \\
\pm 0.0067\end{array}$ & $\begin{array}{c}0.531 \\
\pm 0.054\end{array}$ & $\begin{array}{c}0.0198 \\
\pm 0.0041\end{array}$ & $\begin{array}{c}0.0365 \\
\pm 0.0046\end{array}$ \\
\hline 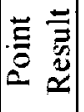 & $\begin{array}{l}\text { USM3Dns } \\
\text { Case2 }\end{array}$ & $\begin{array}{c}0.123 \\
(+0.003)\end{array}$ & $\begin{array}{c}0.539 \\
(+0.008)\end{array}$ & $\begin{array}{c}0.0190 \\
(-0.0008)\end{array}$ & $\begin{array}{c}0.0337 \\
(-0.0028)\end{array}$ \\
\hline
\end{tabular}

Table 7. Comparison of USM3Dns lift-curve slope and drag-polar parameters to statistical data ${ }^{16}$. 

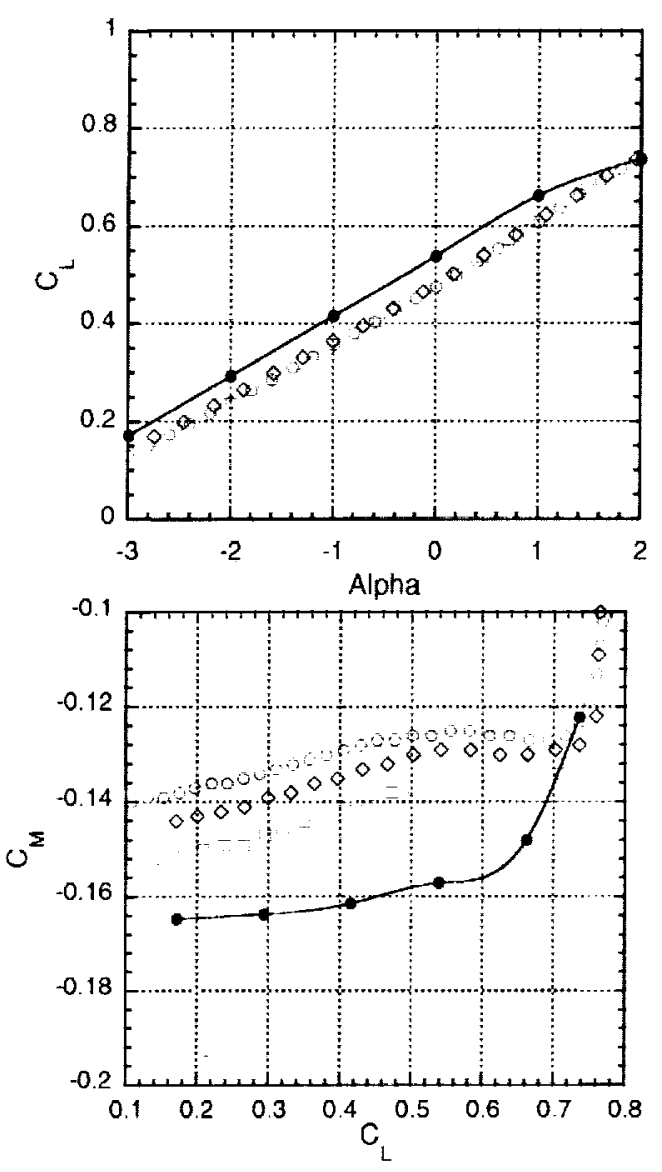

Figure 11. Force and moment data for DLR-F4. Case 2:

experimental composite. This suggests that CFD data can be as useful as wind tunnel data for studying trends in aerodynamic forces.

The last two optional Cases 3 and 4 are representative of constant $C_{L}$ drag rise predictions for eight different Mach numbers and three values of $C_{L}$. The Mach sweep, drag rise curves are useful for analyzing the drag characteristics of commercial aircraft and are often used by the industry. Figure 12 illustrates the predicted drag rise curves, along with the experimental data, for $C_{L}$ values of $0.4,0.5$, and 0.6 . At the $C_{L}$ of 0.4 , the computation agrees with the experiments reasonably well, however, the agreement degrades with increasing lift and Mach number where additional aeroelastic deformation and separation onset occur. Recall that the computational grid was constructed on a single-point surface estimate of aeroelastic deformation. Additional load-induced grid deformations are needed for more accurate prediction of aerodynamic coefficients across the Mach range. The prediction of separation onset is generally difficult due to sensitivities associated with transition and turbulence models. Although the drag is generally under predicted at these conditions, the onset of the drag rise has been properly captured by the current computations. As in the preceding cases, the mismatch in drag rise between CFD and experiments was common among the workshop CFD results. $\mathrm{M}_{\infty}=0.75$, and $\operatorname{Re}_{\text {mac }}=3.0 \times 10^{6}$.

\section{CONCLUDING REMARKS}
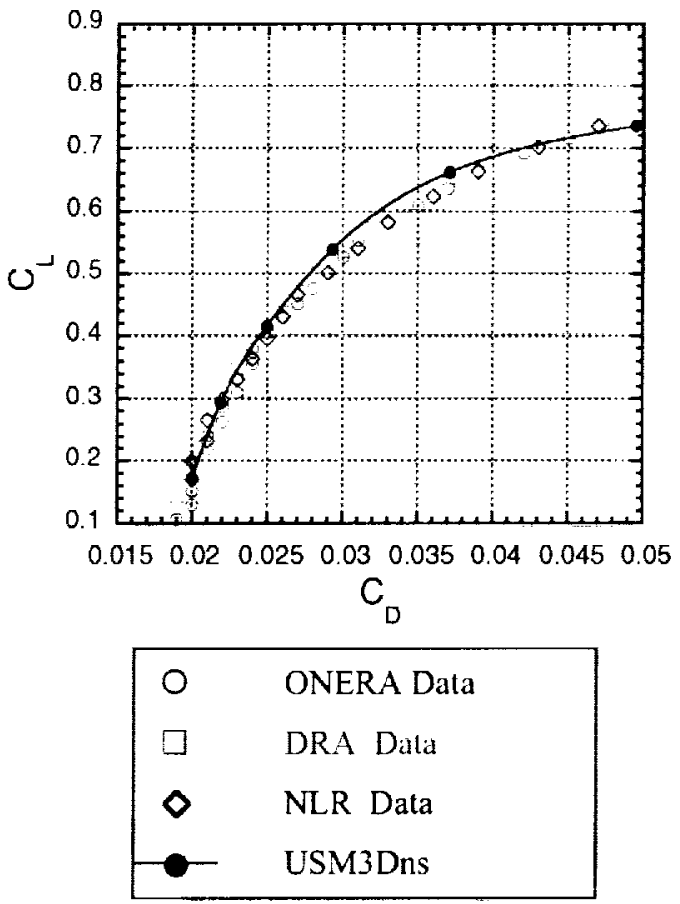

The specifications of three unstructured tetrahedral grids that were generated for the first AIAA Drag Prediction Workshop held at the $19^{\text {th }}$ AIAA Applied Aerodynamics Conference in Anaheim, CA, 9-10 June 2001 are presented. The underlying grid generation methodology embodied in the VGRIDns code is also reviewed. The VGRIDns code is part of a complete flow analysis system known as TetrUSS. Special emphasis is placed on the utility of this system as reflected by ease of use, and total turnaround time from CAD to final postprocessed drag polar solutions in days.

An assessment of the TetrUSS flow solver USM3Dns for predicting drag on a transonic transport configuration is made relative to three experimental data sets and a statistical composite of 35 CFD results from a range of structured and unstructured flow solvers using one- and two-equation turbulence models. Over 30 USM3Dns flow solutions on the DLR-F4 configurations were generated for this study with no experienced difficulty. Each solution required between 1.7 and 4.2 wallclock hours to run on 48 processors of the NASA Origin 2000 NAS computer. The assessment led to the following conclusions: 
1. Initial studies exposed a deficiency in the USM3Dns hux limiter and demonstrated that the limiter may not be needed for the present class of applications.

2. The available DI.R-F4 experimental data set should only be considered as a guide in this study due to the number of issues clouding the correlations. The more useful focus of an assessment should be on comparisons to the statistical composite of CFD solutions from the Drag Prediction Workshop.

3. A comparison of predicted drag from USM3Dns to the larger population of CFD codes has demonstrated that its accuracy for predicting drag at transonic cruise conditions using a tetrahedral cell-centered scheme coupled with a wall function boundary condition is well within that of other structured and unstructured codes solving the Navier-Stokes equations to the wall. The wall function is beneficial for reducing solution stiffness and the required number of cells across the boundary layer.

4. Several polar related slope parameters, such as liftcurve slope, lift at zero angle of attack, drag at zero lift, and span efficiency factor are compared against workshop experimental and CFD results. USM3Dns results are well within the scatter for each of these parameters, and generally within the scatter of the experimental composite. This suggests that CFD data can be as useful as wind tunnel data for studying trends in aerodynamic forces.

5. The combination of rapid grid generation and flow solution turnaround exhibited by VGRIDns and USM3Dns, respectively, along with the demonstrated accuracy for predicting aerodynamic forces and moments as compared to other structured and unstructured solvers underscores the practicality and usability of the TetrUSS system.

The comparison of USM3Dns solutions to a statistical composite from a larger body of CFD codes has been very beneficial. As a result, several key issues were surfaced that merit further consideration in future workshops. Among these are static aeroelasticity, use of flux limiters, now transition, and grid resolution in the trailing-edge wake region.
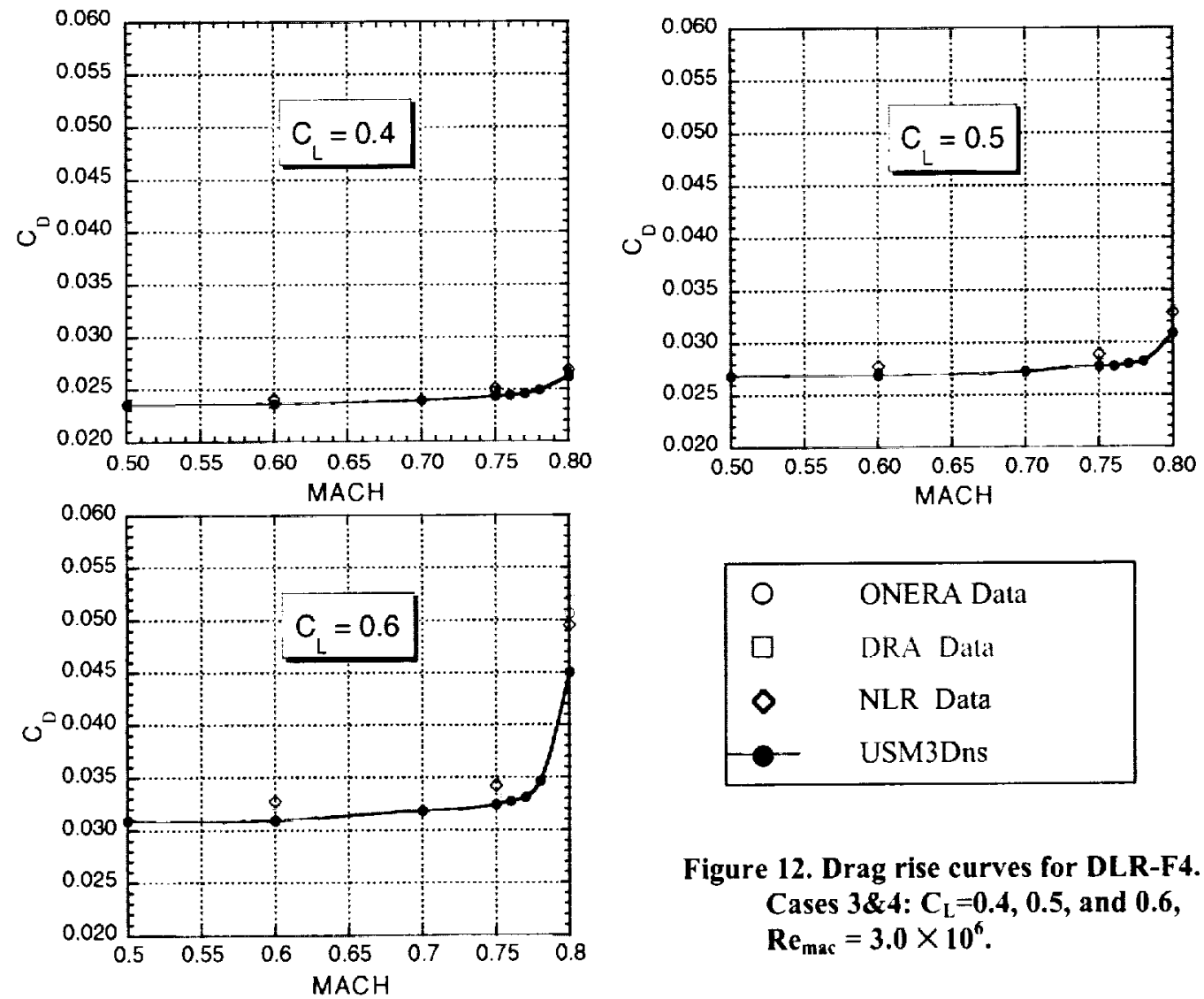

Figure 12. Drag rise curves for DLR-F4. Cases 3\&4: $C_{L}=0.4,0.5$, and 0.6 , $\operatorname{Re}_{\mathrm{mac}}=3.0 \times 10^{6}$. 


\section{REFERENCES}

1. Anon, "Proceedings of the First AIAA CFD Drag Prediction Workshop,"

hıp:/ad-www.larc,nasa,gov/tsab/cfdlarc/aiaa-dpw' index.html, 2001.

2. Levy, D. W., Zickuhr, T., Vassberg, J., Agrawal, S., Wahls, R.A., Pirzadeh, S.Z., and Hemsch, M.J., "Summary of Data from the First AIAA CFD Drag Prediction Workshop," AIAA Paper 2002-0841, January 2002.

3. Redeker, G., "DLR-F4 Wing-Body Configuration", A Selection of Experimental Test Cases for the Validation of CFD Codes, AGARD Report AR-303, Aug. 1994.

4. Haase, W. et. al., "ECARP - European Aerodynamics Research Project: Validation of CFD Codes and Assessment of Turbulence Models," Notes on Numerical Fluid Mechanics, Vol 58, 1997.

5. Frink, N.T., Pircadeh, S.Z., Parikh, P.C., and Pandya, M.J., "The NASA Tetrahedral Unstructured Software Sysytem (TetrUSS)," The Aeronautical Journal, Vol. 104, No. 1040, October 2000, pp. 491-499.

6. Pirzadeh, S.Z., "A Solution-Adaptive Unstructured Grid Method by Grid Subdivision and Local Remeshing," Journal of Aircraft, Vol. 37, No. 5, pp. 818-824, 2000.

7. Löhner, R. and Parikh, P., "Generation of Three Dimensional Unstructured Grids by the Advancing Front Method," International Journal of Numerical Methods in Fluids, Vol. 8, 1988, pp. 1135-1149.

8. Pirzadeh, S., "Three Dimensional Viscous Grids by the Advancing-Layers Methods," AIAA Journal, Vol. 34, No. 1, 1996, pp. 43-49.

9. Samareh, J., "GridTool: A Surface Modeling and Grid Generation Tool," Proceedings of the Workshop on Surface Modeling, Grid Generation, and Related Issues in CFD Solutions, NASA CP-3291, May 9-11, 1995.

10. Pirzadeh, S., "Structured Background Grids for Generation of Unstructured Grids by Advancing Front Method," AIAA Journal, Vol. 31, No. 2, 1993, pp. 257 265.

11. Pirzadeh, S., "Recent Progress in Unstructured Grid Generation," AIAA Paper 92-0445, January 1992.

12. Frink, N.T., "Tetrahedral Unstructured Navier-Stokes Method for Turbulent Flows," AlAA Journal, Vol. 36 , No. 11, pp. 1975-1982, 1998.

13. Bhat, M.K. and Parikh, P.C., "Parallel Implementation of an Unstructured Grid-Based Navier-Stokes Solver", AIAA Paper 99-0663, January, 1999.
14. Parikh, P.C., "Application of a Scalable, Parallel, Unstructured-Grid-Based Navier-Stokes Solver", AIAA 2001-2584, June 2001.

15. See "Boundary Condilions" in USM3Dns User's Online Manual at URL: http:/ad-www.larc.nasa.gov/ tsab/usm3d/usm3d_52_man.html.

16. Hemsch, M., "Statistical Analysis of CFD Solutions from the Drag Prediction Workshop", AIAA 20020842 , January 2002.

17. Vassberg. J., "Enhancement of AGARD-AR-303 Data”, hitp://ad-www.larc.nasa.gov/tsab/cfdlarc/aiaadpw/pdf T_Data_Enhancement.pdf, Presented at June 2001 AIAA Drag Prediction Workshop, Anaheim, CA, Accessed October 12, 2001. 